\title{
INSTRUMENTO PARA IDENTIFICAÇÃO DOS ELEMENTOS PEDAGÓGICOS DO ELEARNING NO CENÁRIO EMPRESARIAL
}

\author{
ELEARNING PEDAGOGIC IDENTIFICATION INSTRUMENT FOR THE \\ BUSINESS ENVIRONMENT
}

\author{
INSTRUMENTO PARA IDENTIFICACIÓN DE LOS ELEMENTOS \\ PEDAGÓGICOS DEL ELEARNING EN EL CENARIO EMPRESARIAL
}

\author{
Daniela Melaré Vieira BARROS ${ }^{1}$ \\ Cláudia NEVES ${ }^{2}$
}

\begin{abstract}
RESUMO: O presente trabalho resulta do estudo realizado numa empresa portuguesa sobre a formação em eLearning. A partir do estudo destacamos alguns elementos de natureza pedagógica que se evidenciaram. Esta discussão é contextualizada no âmbito da sociedade em rede e das necessidades emergentes da formação contínua de pessoas. Neste contexto, o eLearning assume-se como um elemento central para o desenvolvimento e potenciação de cenários de formação contínua nos meios empresariais. Os principais objetivos do trabalho realizado foram construir um instrumento de avaliação pedagógica para cursos em eLearning empresarial, a partir dos elementos da formação contínua online; possibilitar algumas diretrizes didáticopedagógicas de análise para cursos em eLearning empresarial. Apresentamos neste artigo algumas pistas de discussão em torno da temática do eLearning empresarial, suportados por referenciais bibliográficos, reflexões e discussões que acompanharam as diversas fases do estudo, nomeadamente: a observação não participante de cursos em eLearning, a construção de um instrumento de análise de cursos de eLearning empresariais a partir do referencial pedagógico e a validação do mesmo na aplicação aos cursos observados.
\end{abstract}

PALAVRAS-CHAVE: E-Learning. Empresa. Instrumento de avaliação pedagógica.

RESUMEN: El presente trabajo resulta del estudio realizado en una empresa portuguesa sobre la formación en eLearning. A partir del estudio tenemos algunos elementos de naturaleza pedagógica que se evidenciaron. Esta discusión es en el contexto de la sociedad en red y de las necesidades emergentes de la formación continua. En este contexto, eLearning se asume como un elemento central para el desarrollo de escenarios de formación continua en los medios empresariales. Los principales objetivos del trabajo realizado fueron construir un instrumento de evaluación pedagógica para cursos en eLearning en la empresa, a partir de los elementos de la formación continua online; y posibilitar algunas directrices pedagógicas de análisis para cursos en eLearning empresarial. En este artículo se presentan algunos caminos para discutir la temática del eLearning empresarial, con referencias bibliográficas, reflexiones y discusiones que acompañaron las diversas fases del estudio, la observación no participante de cursos en eLearning, la construcción de un instrumento de análisis de cursos de eLearning empresariales a

\footnotetext{
${ }^{1}$ Universidade Aberta - Lisboa Portugal, Centro de Estudos Interdisciplinares do Século XX - CEIS XX Coimbra, Laboratório de Educação a Distância e Elearning - L@ead-UAb. E-mail: daniela.Barros@uab.pt.

${ }^{2}$ Universidade Aberta - Lisboa Portugal, Laboratório de Educação a Distância e Elearning - L@ead-UAb. E-mail: claudia.Neves@uab.pt.
} 
partir del referencial pedagógico y la validación del mismo en la aplicación a los cursos observados.

PALABRAS CLAVE: E-Learning. Empresa. Instrumento de evaluación pedagógica.

ABSTRACT: The present study results from the study carried out in a Portuguese company about training in eLearning. From the study we have some elements of a pedagogical nature that were evidenced. This discussion is in the context of networked society and the emerging needs of continuous training. In this context, eLearning is a central element for the development of continuous training in business circles. The main objectives of the work were to construct a pedagogical evaluation tool for courses in eLearning in the company, based on the elements of continuous online training; and provide some pedagogical guidelines for the analysis of courses in business eLearning. In this article we present some ways to the discussion of eLearning business, with bibliographical references, reflections and discussions that accompanied the various phases of the study: the non-participant observation of courses in eLearning, the construction of an analysis tool for business eLearning courses from the pedagogical framework and the validation in the application to the observed courses.

KEYWORDS: E-Learning. Business. Pedagogical evaluation instrument.

\section{Introdução}

O impulso inicial para este estudo foi a necessidade da empresa multinacional em conhecer em profundidade o seu modelo de formação em eLearning, para melhorar e satisfazer as necessidades de formação da instituição e dos seus colaboradores nesta modalidade de ensino. Nesse sentido, foi celebrada uma parceria entre a Universidade Aberta e a empresa, que permitisse o desenvolvimento de uma série de iniciativas, entre as quais a concretização de um estudo nos cursos por eles desenvolvidos.

A problemática existente delineada estava na compreensão dos aspetos pedagógicos do eLearning empresarial para aprimorar o potencial educativo deste cenário, melhorando a aprendizagem dos estudantes de formação contínua. Justificavase este estudo pela importância de ter referenciais que nos ajudassem a construir práticas inovadoras em eLearning empresarial que, simultaneamente, atendessem às necessidades emergentes. Além disso, pretendeu-se contribuir para diminuir a necessidade de construir reflexões mais amplas e sistematizar formatos de trabalho direcionados para a aprendizagem via eLearning em contextos empresariais. Para tanto, o estudo desenvolvido, de foro qualitativo, foi realizado por meio de análise descritiva, suportada por referenciais bibliográficos, reflexões e discussões realizadas, também, no 
espaço de diálogo do grupo de eLearning empresarial da Universidade Aberta, vinculado à Pró Reitoria de Inovação Pedagógica e ao Laboratório de Educação a Distância e eLearning - LE@d da Universidade Aberta.

O presente documento traz de inovação um instrumento ainda não desenvolvido e que tem como importância a identificação dos elementos pedagógicos de cursos de eLearning em contexto empresarial. Essa identificação facilita análise dos cursos, a identificação dos elementos pedagógicos, a checagem de todos os elementos e a descrição de como o processo didático ocorre. Isso proporciona elementos para análise e posterior melhoria dos aspetos pedagógicos e, consequentemente, a construção da qualidade no processo de ensino e aprendizagem.

A importância desse instrumento reside na possibilidade de avaliar os cursos em desenvolvimento, apontando pontos de melhoria pedagógica, dificuldades na qualidade do processo de ensino e, principalmente, a inovação no formato do curso para os estudantes. A elaboração dos instrumentos decorre de um trabalho consolidado anteriormente, envolvendo fases de pesquisa com métodos de recolha de dados; os resultados desses dados possibilitaram a estruturação do instrumento que será aqui apresentado (Buendia e Cólas, 1998).

Algumas das investigações atuais da área têm apostado nos temas da gestão do conhecimento, aplicativos e softwares relacionados com o desenvolvimento do eLearning nos contextos empresariais. Destacamos o que Leal e Rocio (2014) enfatizam no trabalho do eLearning empresarial, com o uso da cloud computing (computação em nuvem), que oferece os recursos de computação necessários (hardware e software) como um serviço, destacando as vantagens, a nível das organizações empresariais, da tecnologia de cloud computing num sistema de eLearning. Já em outras investigações, a gestão do conhecimento e a aprendizagem organizacional nas empresas aparecem como elementos de análise do entorno do eLearning empresarial (D’Árisbo, et al., 2016). Nada em específico foi desenvolvido sobre a avaliação direta dos cursos na perspetiva pedagógica.

O que fundamenta a importância desse tipo de instrumento são os processos de avaliação qualitativa dos cursos. Não existe nada específico para a avaliação dos cursos em contexto de eLearning empresarial. Por esse motivo, é essencial estabelecer elementos e instrumentos de avaliação para a melhoria contínua e ajustes do trabalho que se está a desenvolver (THOMPSON, 2004). É essencial pensar como o conhecimento científico universitário pode contribuir para os processos de 
desenvolvimento profissionais e de formação em contexto real e prático. A qualificação que as empresas realizam com os seus funcionários fornecem competências que podem e devem ser social e institucionalmente reconhecidas. A formação em eLearning possibilita um caminho para este reconhecimento, na medida em que a sistematização, estruturação e organização dos cursos exige uma série de elementos educacionais caracterizados de forma qualitativa, exigindo uma série de competências e gestões diretamente relacionadas com a qualidade pedagógica dos conteúdos e do processo.

Neste documento estarão sistematizados alguns aspetos teóricos relacionados com o eLearning e os contextos de Aprendizagem em Educação a Distância, bem como a análise de algumas teorizações em torno do eLearning enquanto estratégia de formação em cenários empresariais. Apresentamos, também, o estudo desenvolvido para a construção do instrumento pedagógico de análise.

A estrutura deste documento segue os seguintes pontos: no primeiro, apresenta, de forma sintetizada, algumas reflexões teóricas em torno do eLearning, mais precisamente o eLearning empresarial enquanto estratégia de formação e aprendizagem; no segundo, os objetivos que nortearam todo o estudo, descrevendo o roteiro metodológico desenvolvido; no terceiro ponto, apresenta o instrumento construído, com suas diretrizes e elementos.

\section{Questões norteadoras da investigação}

O principal objetivo do trabalho realizado foi construir um instrumento de avaliação pedagógica para cursos em eLearning empresarial, a partir dos elementos da formação contínua online, possibilitando algumas diretrizes didático-pedagógicas de análise para cursos em eLearning empresarial.

Para abordar este objetivo central especificamos as sequintes questões de pesquisa:

1. Quais os aspetos pedagógicos necessários para serem inseridos na estrutura de um curso em eLearning empresarial?

2. Dos principais aspetos pedagógicos desenvolvidos nos cenários de eLearning empresarial, quais os indicadores a serem considerados para a avaliação dos cursos?

\section{Conteúdo Teórico}

RPGE- Revista on line de Política e Gestão Educacional, Araraquara, v.21, n.3, p. 1517-1549, set./dez., $2017 . \quad$ ISSN: 1519-9029 
Este tópico é dividido em dois temas: "O eLearning nos cenários de formação empresarial: breves aproximações", "eLearning: aspetos pedagógicos da estrutura de um curso online a partir do modelo pedagógico da Universidade Aberta”. O objetivo é desenvolver uma estrutura teórica que possa apoiar o desenvolvimento do instrumento que propomos mais tarde.

\section{O eLearning nos cenários de formação empresarial: breves aproximações}

A sociedade da informação e do conhecimento, a denominada sociedade digital, está em constante atualização e inovação nos processos de informação, produtos e sistemas. O meio empresarial está imerso neste processo, tal como todos os outros contextos da sociedade. O desafio constante das empresas está em possibilitar atualização através da aprendizagem e de forma abrangente com o online.

O eLearning passou a ser uma estratégia a ser desenvolvida, testada e ampliada no contexto da internet, a fim de aproveitar o potencial da tecnologia do eLearning para uma mudança benéfica e sustentável nos contextos empresariais (RUDESTAN; READSCHOENHOLTZ, 2010). A sustentabilidade desses processos passa pela aprendizagem e o desenvolvimento de competências e habilidades das pessoas. É assertivo dizer que a tecnologia da internet é a chave para uma revolução profunda no aprendizado, uma estratégia aceita nos contextos de formação empresarial. Para além desse aspecto, o mundo empresarial passou a considerar que a aprendizagem é mais do que um treinamento ou informações soltas sobre determinado assunto; com o eLearning e os modelos de plataforma e desenvolvimento de cursos, a atenção pedagógica e a forma de aprendizagem e o ensino ganharam espaços de forma qualitativa.

O eLearning envolve mudança de tecnologia que, por sua vez, exige uma mudança de cultura profunda dentro da empresa. Esse é um ponto crucial quando se busca a aceitação de um projeto dessa natureza. A aprendizagem, para os contextos empresariais, é um meio para atingir os objetivos de desempenho e desenvolvimento de competências, tradicionalmente é denominado treinamento, uma metodologia padrão para facilitar e melhorar o desempenho, tendo a instrução como processo específico.

O denominado treinamento, termo mais utilizado no meio empresarial, tem quatro elementos principais: uma intenção de melhorar o desempenho de maneira específica, geralmente obtida por meio de avaliações das necessidades e refletida nos objetivos instrucionais e de aprendizado; um design que reflete a estratégia instrucional 
que melhor se adapta aos requisitos do aprendizado e aos atributos do aprendiz; o meio e a mídia através dos quais a instrução é transmitida, que podem incluir a sala de aula, uma variedade de tecnologias, o estudo independente ou uma combinação de metodologias; e, por fim, uma avaliação mais formalizada ou habilidade de certificação (ROSENBERG, 2002).

Pode-se observar que, ainda hoje, o eLearning ocorre principalmente dentro das grandes empresas do setor das Tecnologias da Informação e Telecomunicações e que, fora disso, nas pequenas e médias empresas há pouca atividade relacionada diretamente ao eLearning (HAMBURG et al, 2005; MILL et al, 2004). Alguns autores afirmam que o uso do eLearning passa basicamente pela formação de competências em tecnologias da informação, como por exemplo habilidades de programação, etc. (SKILLSOFT, 2001; BRENNAN, 2004).

$\mathrm{O}$ desenvolvimento do eLearning empresarial tem ainda pela frente alguns constrangimentos e problemas a serem enfrentados. Muitos dos problemas percebidos são, no entanto, baseados em conceções errôneas ou preconceitos que têm origem numa suspeita geral de um processo educacional não dirigido pelo professor. Existe medo de altos custos e despesas gerais para a manutenção. A outra dificuldade é que a maioria desses cenários empresariais não têm uma infraestrutura adequada para a aprendizagem. Em geral, os funcionários não têm tempo para estudar e, com frequência, não são financiados para prosseguir a formação (CEDEFOP, 2003).

Outro obstáculo para mudar radicalmente a forma como o treinamento é oferecido reside na cultura organizacional, especialmente na cultura de aprendizagem (WADE, 2003). Normalmente, cada empresa tem e/ou estabelece uma cultura de aprendizagem, ou seja, a forma específica como a organização ensina os seus funcionários a aprender e serem apoiados ao longo do caminho. Dentro dessa cultura, o objetivo final está no conteúdo a ser apresentado e nas habilidades para dominar e aplicar esse conteúdo (HAMBURG, LINDECKE, TERSTRIEP, 2005).

As habilidades para dominar e aplicar o conteúdo são o que compõem a cultura de aprendizagem de uma organização. Se a cultura de aprendizagem estabelecida pela empresa for altamente dependente, é necessário começar a introduzir nos funcionários habilidades que promovam uma abordagem mais independente, que suportam assim a sua cultura da melhor maneira possível. Uma solução para facilitar essa transição para uma cultura de aprendizado "eletrônica" é misturar a aprendizagem tradicional com 
soluções de eLearning, de forma moderada, mas também inovadora (HAMBURG et al, 2003).

Outro aspeto necessário em contextos empresariais é conhecer muito bem o seu público para os cursos de eLearning. Conhecer o seu público pode fazer a diferença entre um curso de eLearning eficaz e um curso de eLearning que está aquém das expectativas. O que deve ser pensado incialmente é se o seu público-alvo de eLearning está se matriculando em seu curso de eLearning ou está em seu programa de treinamento com um propósito. A fim de desenvolver um curso de eLearning eficaz deve-se predeterminar a finalidade, como por exemplo verificar se o curso em eLearning está destinado a ajudar os alunos a mergulhar num determinado tópico ou ensinando uma tarefa específica (PAPPAS, 2014).

Os alunos têm a sua própria história cultural e educacional, bem como o seu próprio conjunto de aprendizagens prévias, as suas competências, habilidades e perfis de experiência. No entanto, há provavelmente alguns aspetos de formação que eles têm em comum? Qual é o seu nível de experiência no local de trabalho? Eles vão ser capazes de compreender os conceitos que você está incluindo ou você deve estar apresentando o conteúdo de uma maneira mais simples e direta? Tenha em mente que o objetivo final é o que o aluno seja capaz de aprender (Gutierrez, 2015). Igualmente, ao projetar o seu curso de eLearning, é importante pensar sobre como os alunos estarão acessando o conteúdo (PAPPAS, 2014).

O eLearning em cenários empresariais é tema de análise sobre a sua eficiência e eficácia para a aprendizagem e treinamento de competências pessoais (BROWN; FORD, 2002, DEROUIN; FRITZSCHE; SALAS, 2004). Essas habilidades envolvem o desenvolvimento de competências verbais e não-verbais que tradicionalmente são desenvolvidas presencialmente.

Essas, entre outras questões, fazem parte das análises sobre o eLearning empresarial, portanto, oferecem-nos algumas diretrizes sobre as necessidades e os elementos de importância para a aprendizagem num cenário com características específicas. A partir dessas assertivas, a ideia de desenvolver um instrumento para analisar os cursos online passa pela identificação desses componentes ressaltados pela literatura.

\section{E-Learning: aspetos pedagógicos da estrutura de um curso online a partir do modelo pedagógico da Universidade Aberta}


Existem diversos modelos e estruturas com elementos pedagógicos para o eLearning, desde plataformas caracterizadas como estruturas didáticas, até modelos para a construção de cursos online. Neste estudo optamos por destacar um modelo pedagógico consolidado: o modelo pedagógico virtual de educação a distância e eLearning da Universidade Aberta, Portugal (Pereira et al, 2007). Esse modelo, como primeiro modelo em língua portuguesa construído e fundamentado para cursos online, é premiado e reconhecido em contextos nacionais e internacionais pela sua inovação na época em que foi desenvolvido. Importa referir que este modelo é um documento orientador em constante revisão, com vista a melhorá-lo e atualizá-lo à medida que os avanços científicos vão surgindo.

O modelo pedagógico da Universidade Aberta está fundamentado em quatro grandes linhas: a aprendizagem centrada no estudante, flexibilidade, interação e inclusão digital (GARRISON, 1989; ARETIO et al, 2007; ANDERSON, 2008; GARRISON; ANDERSON, 2003; DOWNES, 2007). Estas linhas norteiam a organização do ensino, o papel do estudante e do professor, a planificação, concepção e gestão das atividades de aprendizagem a propor aos estudantes, a tipologia de materiais a desenvolver e a natureza da avaliação das competências adquiridas.

No caso particular da Universidade Aberta, o modelo pedagógico assenta no eLearning avançado, utiliza a plataforma Moodle adaptada à Instituição e sua organização, em linhas gerais e de forma objetiva, é composta pelos seguintes elementos:

O Plano da Unidade Curricular, que pode ser denominado o documento-guia norteador do processo de aprendizagem. Ali o estudante encontrará os objetivos a atingir, as competências a desenvolver, os conteúdos e os recursos que utilizará para a aprendizagem, o calendário e os modos de avaliação e a organização do cartão de aprendizagem com as indicações para a elaboração dos e-fólios adstritos a este elemento. Esses itens correspondem a todo o conjunto para que o processo de ensino e aprendizagem ocorra.

As atividades formativas são o conjunto de atividades propostas para que o estudante desenvolva a sua aprendizagem de acordo com o conteúdo estudado. Não têm valores atribuídos e são autocorrigidas pelo próprio estudante, com as indicações de avaliação disponibilizadas. 
Os e-fólios são as atividades realizadas durante o semestre, aos quais são atribuídos valores. São no máximo três atividades e de acordo com os conteúdos estudados na Unidade Curricular.

Os Fóruns de trabalho e os Fóruns de dúvidas são para a comunicação, o diálogo e a reflexão referentes aos conteúdos estudados; o primeiro (entre estudantes) e o segundo (dos estudantes com os docentes). Existem também fóruns de ajuda e de notícias que são direcionados a informações e problemas de ordem técnica que possam surgir.

A avaliação contínua e/ou exame são as modalidades de avaliação de escolha possíveis, às quais os estudantes podem optar no início de cada semestre em cada Unidade Curricular. Aqueles que escolhem a avaliação contínua devem realizar os efólios e o p-fólio (prova final); aqueles que escolhem o exame realizam somente a prova final (exame).

Os elementos dentro do âmbito didático-pedagógico que sustentam o modelo da Universidade Aberta, e que colocaremos em destaque neste artigo, serão as bases onde daremos prioridade às reflexões sobre o eLearning empresarial. Acredita-se que esses elementos podem ser complementados e potencializados para a aprendizagem em contextos empresariais.

Para além dessa estrutura pedagógica definida, a instituição conta também com a experiência dos docentes e a constante preocupação com a atualização e a inovação. Para isso, utilizam interfaces e recursos disponíveis na web que convergem com a plataforma, dentro ou fora dela; são essas, entre outras, as inovações que ocorrem nos processos de construção dos cursos da instituição.

A principal função de um modelo pedagógico é orientar todas e quaisquer atividades educativas, sobretudo as que estão por detrás do currículo, da elaboração de materiais didático-pedagógicos, dos processos de estudo e aprendizagem do formando e os processos de avaliação da própria aprendizagem.

Os aspetos pedagógicos da estrutura de um curso online abrangem uma relação de comunicação e convergência dos: conteúdos; objetivos e competências; atividades; interação; estudantes e avaliação. Segundo Lacotte (1994 apud CLEMENTINO, 2008), a comunicação entre professor e alunos organiza-se tendo em conta um acordo tácito; dentro do online essa comunicação é um processo convergente entre conteúdos, interação, atividades e avaliação. Existem ainda outros aspetos que envolvem o diálogo e a distância transactional (MOORE, 1993), teorias e conceitos que fundamentam os 
aspetos da didática e dos processos de comunicação no online, mas que aqui não serão desenvolvidas. O mais importante a considerar é que para o eLearning em contexto empresarial todos os elementos pedagógicos em destaque devem ser adaptados, mas definitivamente devem ser os elementos-base dessa adaptação.

\section{Roteiro metodológico}

As opções metodológicas deste estudo basearam-se numa significativa diversidade de estratégias de recolha de informação, privilegiando o recurso a metodologias qualitativas, tendo em conta o objeto do estudo.

Não optamos por denominar o trabalho desenvolvido por estudo de caso, que para Yin (2005) trata-se de uma abordagem metodológica de investigação quando queremos compreender, explorar ou descrever acontecimentos e contextos complexos, nos quais estão simultaneamente envolvidos diversos fatores. Porém, devido à dimensão do trabalho, que limita a introdução de elementos de informação complementares que poderiam conduzir a processos de triangulação de dados, assim como uma maior contextualização dos estudos, optou-se por designá-lo apenas por estudo para a construção de um instrumento de identificação.

A realização do estudo aqui descrito teve como sustentação teórica as referências do modelo pedagógico da Universidade Aberta (PEREIRA et al, 2007) e demais fundamentações que sustentam os aspetos pedagógicos do eLearning, como: Rudestan e Read-Schoenholt (2010), Garrison (1989), Aretio et al (2007), Anderson (2005), Garrison e Anderson (2003) e Downes (2007).

Como métodos de recolha e análise de dados, selecionamos a observação não participante e a análise comparativa. A utilização da observação não participante como meio de adentrar o mundo específico do contexto dos estudos organizacionais tem sua importância crescente. Uma das razões é não haver outra forma do pesquisador conseguir acesso a determinado campo. Outra consideração do método recai sobre a possibilidade de o pesquisador aprender mais sobre as atividades das pessoas em seu contexto natural (KAWULICH, 2005), bem como a possibilidade do pesquisador observar e, de certa forma, experienciar, não somente observando o que está acontecendo, mas também sentindo (SAUNDERS; LEWIS; THORNHILL, 2000), é essencial para este tipo de estudo realizado. 
A análise comparativa não deve ser confundida com uma técnica que leva ao levantamento de dados empíricos; o uso da comparação enquanto perspetiva de análise possui uma série de implicações situadas no plano epistemológico. Existem múltiplas estratégias de abordagem dos objetos empíricos. É inegável que para isso exista a formulação de determinadas hipóteses que, para alguns autores, continua sendo um dos principais objetivos do método comparativo (CARDOSO; BRIGNOLI, 1975).

Os procedimentos utilizados foram a seleção de séries de fenômenos que fossem efetivamente comparáveis; a definição dos elementos a serem comparados; e a generalização. Os procedimentos utilizados foram os balizadores capazes de garantir a correta articulação entre os dados empíricos e a teoria na construção e explicação do conhecimento (SCHNEIDER; SCHIMITT, 1998).

As duas hipóteses criadas a partir dessa perspetiva, dentro da análise comparativa, foram: existe uma falta de estrutura didático-pedagógica na concepção dos cursos em eLearning empresarial que pode ser completada; os cursos em eLearning empresarial não contemplam todos os elementos didático-pedagógicos para um curso online. A análise comparativa dos aspectos do modelo pedagógico da Universidade Aberta e as experiências das investigadoras neste contexto, com os elementos encontrados na observação realizada, serão melhor exploradas nos resultados apresentados mais à frente.

\section{Design de investigação}

Seguindo Hill et al (2012), adotamos a teoria da generalização para explorar a construção do instrumento, a sua dimensionalidade, e para determinar a sua confiabilidade. Comparado com a teoria clássica do teste, a teoria da generalização é mais informativa e útil nos sistemas educacionais, porque a teoria clássica de testes considera apenas uma fonte de medição de cada vez. Além disso, não resulta com situações de observação. Um estudo com base nesta teoria da generalização pode acomodar qualquer situação observacional. Um estudo utilizando essa assertiva vê, por exemplo, um aspecto observado como uma amostra dentro de um universo de observações admissíveis. Cada aspecto pode ser chamado de faceta.

A teoria da generalização melhora a decisão de um estudo, utiliza as informações de um estudo para construir um design de pontuação para um propósito específico (SHAVELSON; WEBB, 1991). 
Considerando esta assertiva, a estrutura do design de investigação foi estabelecida a partir da construção do instrumento de observação, a observação realizada, os resultados e a comparação com os elementos do modelo pedagógico da Universidade Aberta, resultando na construção do instrumento para análise de cursos em eLearning empresarial.

Em síntese, o design do estudo realizado pode ser visualizado da seguinte forma:

Figura 1: Design metodológico da investigação realizada

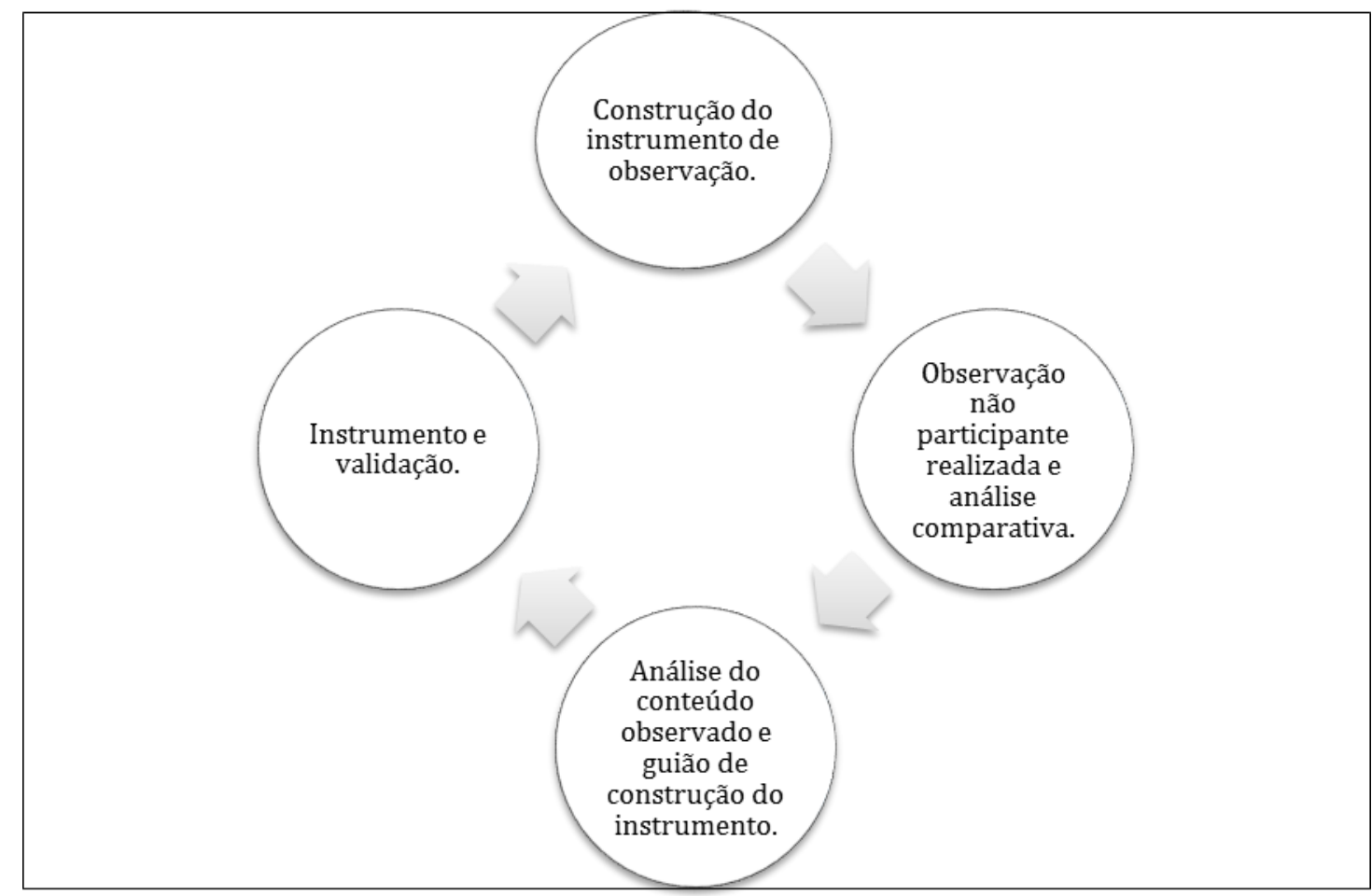

Fonte: Elaboração própria

\section{Etapas da investigação realizada para a construção do instrumento}

A partir do design de investigação definido, descrevemos as etapas a seguir para a construção do instrumento. Essas etapas foram desenvolvidas ao longo de três anos de trabalho, entre os anos de 2014 e 2016.

Quadro 1: Etapas da investigação realizada para a construção do instrumento.

Etapas de elaboração do Descrição das ações

instrumento

la etapa-Pesquisa Levantamento de fontes e das referências bibliográficas tendo como bibliográfica e referencial teórico obras de autores em conformidade com as diretrizes 
hemerográfica em bancos

de dados nacionais e internacionais

2 a etapa - Definição de parâmetros de avaliação através da observação não participante

3 a etapa - Elaboração dos itens do instrumento

4a etapa - Definição da escala de respostas

5 a etapa - Construção dos itens de identificação

6a etapa - Elaboração da primeira versão do instrumento

7a etapa - Validação de conteúdo e aparente requeridas pelo tema. Constataram-se poucos registos sobre o tema, não tendo sido encontrado nenhum instrumento sistemático de análise pedagógica de cursos em eLearning empresarial.

Tendo em vista a inexistência de uma escala ou outro tipo de ferramenta que pudesse ser adaptada para a pedagógica desses cursos, foi construído um instrumento próprio para este fim. Para tanto, foi realizada uma observação não participante de dois cursos de eLearning empresarial e a comparação com os referenciais pedagógicos do modelo da Universidade Aberta.

Após a realização da observação e análise, foram elencados os fatores observados e comparados. Com base nestes fatores e nos elementos do modelo pedagógico virtual da Universidade Aberta, foram selecionadas as dimensões (apresentadas no quadro 2) que iriam compor o instrumento desenvolvido.

Tomando por base a definição das dimensões, formaram-se subgrupos para cada uma delas, com base na experiência do Modelo pedagógico da Universidade Aberta e nos autores de referencia da área em questão. Na etapa de construção dos itens, foram amplamente trabalhados com os critérios que a literatura especializada propõe que sejam considerados na sua elaboração.

A partir da elaboração dos itens, passou-se a discutir quais seriam as melhores alternativas da forma de uso e resposta ao instrumento. Concluiu-se que, para este instrumento, o ideal seria para observações em aberto considerando as seguintes questões para cada subgrupo. Existe, sim ou não? Se sim, quais as principais características encontradas na escala utilizada (Morais, 2005).

Optou-se por inserir no instrumento poucos itens relativos a dados de identificação a fim de preservar o máximo possível o anonimato dos cursos. $\mathrm{O}$ cuidado com o sigilo, neste caso, era extremamente importante pelo protocolo realizado com a empresa.

Reunindo os materiais elaborados nas etapas dois, três, quatro e cinco, montou-se a primeira versão do instrumento, que foi posteriormente utilizado por duas estudantes de mestrado que avaliaram outros dois cursos da empresa em questão. Revisou-se criteriosamente esta primeira versão, realizando pequenos ajustes que visavam uma melhor padronização da linguagem empregue na redação dos itens.

Submeteu-se a primeira versão do instrumento a uma avaliação dos professores do grupo de investigação do Laboratório LE@D. Desta forma, a ideia foi realizar uma validação de conteúdo pelos colegas investigadores, buscando determinar a 
apropriação dos itens e dimensões do instrumento. A validação de conteúdo não é determinada estatisticamente, mas é o resultado do julgamento de diferentes juízes ou pessoas de reconhecido saber na área sobre o conteúdo que está sendo medido, os quais analisam a representatividade dos itens em relação aos conceitos avaliados: Anastasi \& Urbina (2000); Fachel \& Camey (2000); Pasquali (2001). Para esses autores, o instrumento possui validade de conteúdo se os itens que o constituem são representativos do universo que ele pretende representar e, além disso, se são, do ponto de vista teórico, indicadores da variável a ser medida. Além da validade de conteúdo propriamente dita, um outro tipo de validade também se relaciona com a análise dos itens: trata-se da validade de face ou validade aparente, a qual se refere ao que o teste mede superficialmente, ou seja, diz respeito à linguagem e à forma como o conteúdo está sendo apresentado Anastasi \& Urbani (2000); Fachel \& Camey (2000); Latiesa (1996). Os pareceres desses colegas indicaram que o instrumento era adequado aos objetivos a que se propunha, sendo o formato da escala e a formulação dos itens elementos facilitadores para sua compreensão e preenchimento.

Fonte: Elaboração própria

\section{Público-Alvo e espaço de investigação}

Para o desenvolvimento da observação não participante, ambas as investigadoras foram inscritas em cursos de eLearning dentro do contexto da empresa em questão, de modo a reunirem todos os dados pertinentes para os objetivos deste estudo. Os cursos eram específicos da área da empresa e estavam na categoria de formação contínua para atendimento ao cliente.

O público que participava nos cursos eram funcionários da empresa que trabalham diretamente com os clientes. Todos tinham contrato com a empresa e participavam regularmente dos treinamentos para a formação contínua no posto de trabalho que ocupavam.

O espaço foram os cursos desenvolvidos em plataforma própria e customizada. As investigadoras receberam senhas e permissões para frequentarem os cursos como usuárias "estudantes", realizando todas as atividades e estudos propostos, mas sem nenhum tipo de interação com formadores ou os outros estudantes. Não podemos detalhar mais o público-alvo e o espaço de investigação, pelo sigilo do trabalho acordado como protocolo. 


\section{Instrumento da observação não participante}

Essa observação não participante foi realizada considerando as seguintes etapas: primeiramente, a observação do curso por completo; numa segunda etapa, a identificação geral das dificuldades e apreciação sobre a realização do mesmo; e numa terceira etapa, a comparação com os referenciais pedagógicos do modelo pedagógico virtual da Universidade Aberta no qual as investigadoras são docentes.

A grelha de observação elaborada pelas investigadoras contou com os seguintes elementos como objetivos da observação: identificar os aspetos pedagógicos dos cursos em eLearning empresarial; elencar as princiapais dificuldades na realização do curso enquanto estudantes e, por fim, comparar com os elementos pedagógicos do modelo da Universidade Aberta de Portugal.

As dimensões da grelha foram os seguintes elementos pedagógicos: os conteúdos; objetivos e competências; atividades; interação; estudantes e avaliação. Esses elementos são comuns ao desenvolvimento de cursos online, como podemos identificar em Pereira et al (2007) e demais fundamentações que sustentam os aspetos pedagógicos do eLearning, como: Rudestan \& Read-Schoenholt (2010), Garrison (1989), Aretio et al (2007), Anderson (2005), Garrison \& Anderson (2003), Downes (2007). Os pontos a observar em cada um dos elementos podem ser visualizados no quadro identificado a seguir:

Quadro 2: Estrutura da grelha de observação utilizada como instrumento de estudo

\begin{tabular}{|c|c|c|c|}
\hline $\begin{array}{c}\text { OBJETIVOS a serem } \\
\text { alcançados com a }\end{array}$ & $\begin{array}{c}\text { Dimensões da observação } \\
\text { para cada objetivo }\end{array}$ & Pontos a observar & $\begin{array}{l}\text { Espaço para os } \\
\text { comentários } d a\end{array}$ \\
\hline $\begin{array}{l}\text { Identificar os } \\
\text { aspetos pedagógicos } \\
\text { dos cursos em } \\
\text { eLearning } \\
\text { empresarial }\end{array}$ & 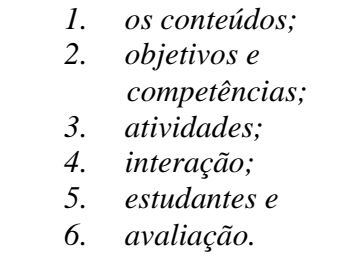 & $\begin{array}{l}\text { Como foi contruído o curso, quais os } \\
\text { objetivos e competências a serem } \\
\text { adquiridos pelos estudantes. Como estão } \\
\text { disponibilizados os conteúdos, como foram } \\
\text { elaboradas as atividades e a avaliação. }\end{array}$ & \\
\hline $\begin{array}{l}\text { Elencar as } \\
\text { principais } \\
\text { dificuldades na } \\
\text { realização do curso }\end{array}$ & $\begin{array}{l}\text { 1. } \quad \text { os conteúdos; } \\
\text { 2. } \quad \text { objetivos } e \\
\text { competências; } \\
\text { 3. } \quad \text { atividades; } \\
\text { 4. interação; } \\
\text { 5. estudantes } e \\
\text { 6. } \\
\text { avaliação. }\end{array}$ & $\begin{array}{l}\text { A usabilidade na realização do curso, fácil } \\
\text { acesso, dificuldade em entender o que é } \\
\text { solicitado, facilidade de leitura e uso dos } \\
\text { aplicativos. Falta de interação entre }\end{array}$ & \\
\hline
\end{tabular}


enquanto estudantes

Comparar com os

elementos

pedagógicos do

modelo da

Universidade Aberta

de Portugal. formadores e colegas. Clareza no conteúdo disponibilizado, disculdades na realização da avaliação e das atividades propostas.

Os elementos pedagógicos do modelo pedagógico da Universidade Aberta baseiam-se em: aprendizagem centrada no estudante, flexibilidade, interação, inclusão. Analisar os itens identificados nos cursos a partir desses eixos.

Fonte: Elaboração própria

O tratamento dos dados recolhidos na observação não participante utilizou a análise do conteúdo observado, anotações e elementos identificados pelas investigadoras. A análise de conteúdo constitui uma metodologia de pesquisa usada para descrever e interpretar conteúdos. Essa análise, conduzindo a descrições sistemáticas, qualitativas ou quantitativas, ajuda a reinterpretar as mensagens e a atingir uma compreensão dos seus significados num nível que vai além de uma leitura comum. A análise do conteúdo foi realizada considerando a frequência que ocorreram determinados objetos; a quantificação simples; a análise de frequências dos temas ou categorias, etc.; a análise de ocorrências identificando quais as características ou atributos que são associados aos diferentes objetos e a avaliação do que é referido, atitudes favoráveis ou desfavoráveis e sistema de valores em relação à experiência prévia ao eLearning (BARDIN, 1977).

A seguir, de acordo com as etapas da observação não participante, descrevemos os resultados obtidos.

\section{Resultados da observação não participante}

\section{$1^{a}$ Etapa}

A primeira etapa da observação dos cursos ocorreu na realização do mesmo; fomos anotando e organizando reflexões num caderno de campo, onde descrevíamos as impressões iniciais, ideias e análises sobre a dinâmica, estratégias e desenvolvimento dos cursos. Também o tipo, formato e qualidade do conteúdo disponibilizado, para além, é claro, das atividades propostas para o estudo e a avaliação. Essas anotações também eram acompanhadas de reflexões comparativas, analíticas e críticas a respeito 
do curso e do formato, sempre tendo como parâmetro o público-alvo, o contexto e a dinâmica necessária de formação. Essas diretrizes obtivemos pela leitura da documentação da empresa e em reuniões com a equipe de trabalho local.

\section{$2^{a}$ Etapa}

Numa segunda etapa, a identificação geral das dificuldades e apreciação sobre a realização do mesmo. Essa segunda etapa foi de análise aprofundada sobre as dificuldades sentidas pelas observadoras enquanto estudantes no curso. Essas dificuldades eram desde os aspetos técnicos em geral como de conteúdo específico, na forma como eram explicitados nas orientações de estudo. As principais dificuldades identificadas foram:

Quadro 3: Resultados gerais qualitativos da observação realizada nos cursos

\begin{tabular}{ll}
\hline \multicolumn{1}{c}{$\begin{array}{c}\text { Elementos Pedagógicos de } \\
\text { Identificação }\end{array}$} & Síntese dos resultados da observação realizada \\
\hline \hline Conteúdo & Os conteúdos estavam sequenciais, sem uma subdivisão identificada. \\
& Portanto, para voltar a um determinado conteúdo era preciso refazer o \\
& curso, não havendo possibilidade de ir diretamente a um determinado \\
& conteúdo. \\
& Não estavam claros os objetivos e competências a desenvolver e \\
& adquirir pelos estudantes. A forma como estavam identificados eram \\
& sobre o curso e sobre o conteúdo e não para ensinar aos estudantes. \\
\hline Objetivos e Competências & As atividades estavam inseridas no meio dos conteúdos, atividades \\
& sequenciais de teste para verificar a informação assimilada. \\
\hline Atividades & Sem possibilidade de interação entre os estudantes e com os \\
& formadores. Sem interação direta ou indireta, síncrona ou assíncrona. \\
& O curso não facilitava o processo de interação e muito menos \\
& mediaçães individuais. Havia somente um fórum de dúvidas quase \\
\hline Interação & não utilizado. \\
\hline \hline Fonaliação & O curso estava totalmente voltado ao formador, sem caracterizar e \\
& focar no estudante, nas suas possíveis dificuldades e necessidades ou \\
& objetivos e competências que eles deveriam adquirir. \\
\hline Estudantes & Somente no final do curso, com perguntas objetivas. Sem uma \\
& avaliação de acompanhamento ou identificação de necessidades. \\
\hline Fante: & \\
\hline &
\end{tabular}

Fonte: Elaboração própria

$3^{a}$ Etapa 
Numa terceira etapa, a comparação com os referenciais pedagógicos do modelo pedagógico virtual da Universidade Aberta na qual as investigadoras são docentes.

Quadro 4: Comparação do Modelo Pedagógico da UAb com os resultados gerais da observação realizada nos cursos

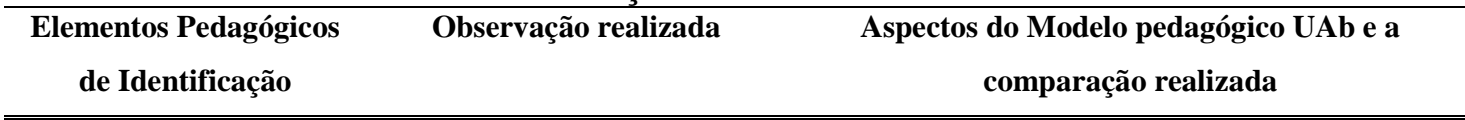

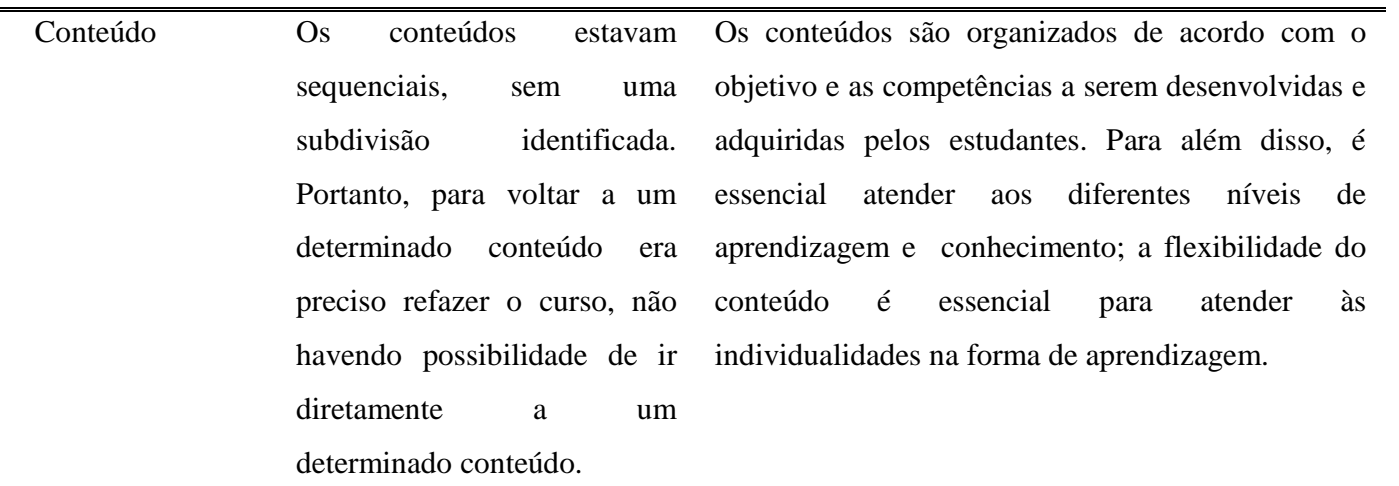

Objetivos e Não estavam claros os A elaboração dos objetivos e competências é parte Competências objetivos e competências a desenvolver e adquirir pelos essencial dos planos de aprendizagem estudantes. A forma como disponibilizados aos estudantes no início do curso, estavam identificados eram devem estar claros e direcionados diretamente ao sobre o curso e sobre o conteúdo e não para ensinar ou desenvolver nos estudantes.

Atividades

Interação

Estudantes
As atividades estavam inseridas no meio dos conteúdos como atividades sequenciais de teste para verificar a informação assimilada.

Sem possibilidade de interação entre os estudantes e com os formadores. Sem interação direta ou indireta, síncrona ou assíncrona. $\mathrm{O}$ curso não facilitava o processo de interação e muito menos mediações individuais. Havia somente um fórum de dúvidas quase não utilizado.

O curso estava totalmente voltado ao formador, sem que os estudantes devem aprender e desenvolver.

As atividades devem ter um papel de verificação dos estudos realizados pelo próprio estudante. Devem ser disponibilizadas atividades para que sejam realizadas entre os diversos conteúdos.

A interação é elemento chave para a qualidade do processo de aprendizagem no online. Existem vários tipos de interação que devem ser considerados, há necessidade de espaços de interação para comunicação entre formadores e entre estudantes. $\mathrm{O}$ atendimento tutorial é necessário no esclarecimento de dúvidas e na motivação do estudante

A estratégias pedagógicas devem priorizar as aprendizagens dos estudantes, além disso a 


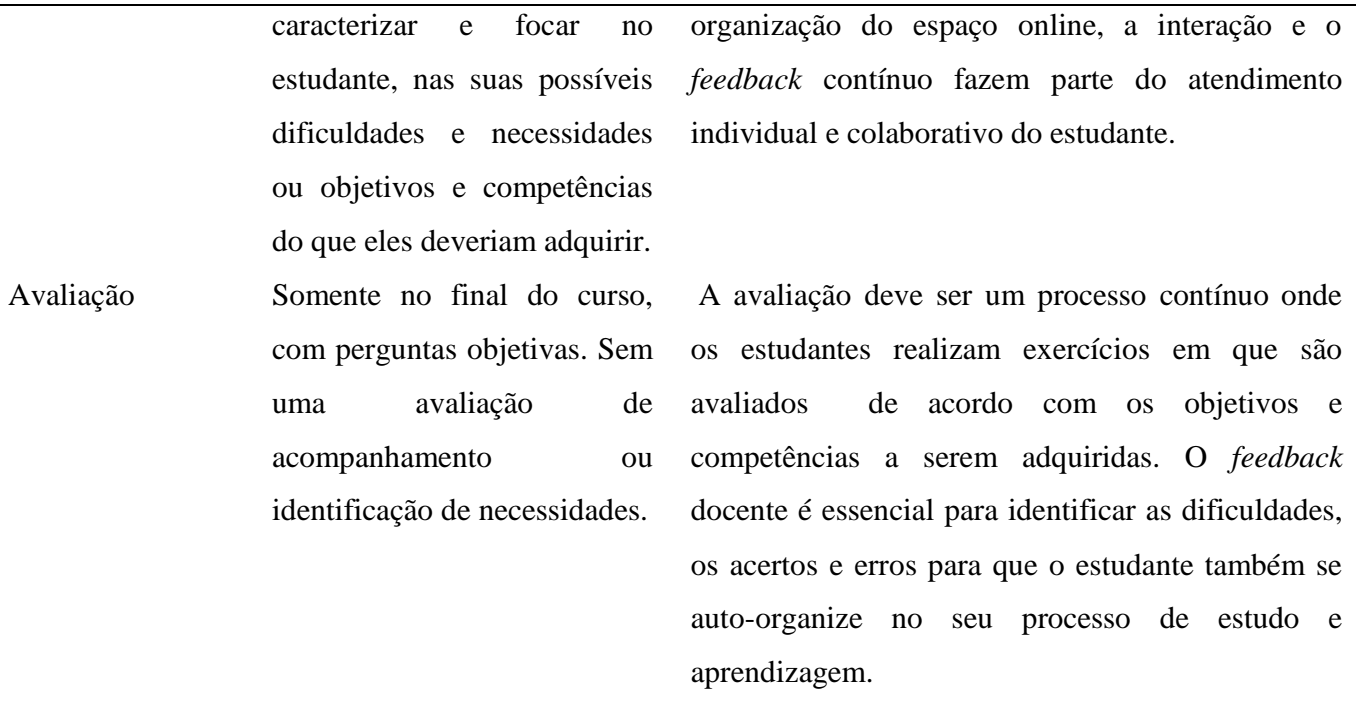

Fonte: Elaboração própria

Os resultados recolhidos facilitaram a construção das unidades de contexto identificadas e a seguir descritas. Os resultados trouxeram algumas particularidades na forma como o eLearning é pensado em instituições empresariais. A lógica é centrada na autoaprendizagem, mas sem considerar elementos de motivação ou um design universal de aprendizagem para a melhor aprendizagem do estudante. A qualidade dos cursos está na construção do material de estudo, no formato de recursos abertos. Esse tipo de material e interface substitui o espaço da plataforma e faz dele uma só unidade de informação onde o curso acontece. Também é preciso considerar a presença virtual e o tempo na organização desses cursos; o tempo é limitado no período do curso, mas o estudante gere completamente a forma de trabalhar, sem prazos a serem cumpridos dentro do curso. Já a presença virtual na interação do estudante acontece somente com os conteúdos em formato de recurso aberto, não se pensa na interação entre formador e estudante e entre estudantes e estudantes: isso surpreende no conceito de interação dos cursos online e o seu significado na aprendizagem das pessoas.

As unidades de contexto foram a junção dos elementos pedagógicos de identificação e os resultados do instrumento de observação analisado. Iniciamos pelos aspectos pedagógicos e didáticos do curso, modelo metodológico utilizado, identificação da forma como o curso foi pensado a partir dos elementos pedagógicos e metodológicos, o estilo e a estrutura de aprendizagem para os estudantes; a seguir, os aspectos técnicos do curso, a plataforma, o design, as ferramentas, os recursos e aplicativos utilizados, todas as ferramentas e interfaces utilizadas com objetivos pedagógicos; os aspectos de conteúdo do curso priorizam quem realiza e como é 
disponibilizado, o material desenvolvido pelo docente, recursos utilizados, orientações de estudos, etc.; também os aspectos assíncronos de comunicação e interação entre estudantes e docentes/tutores - fóruns; diversas formas de interação utilizadas; aspectos de avaliação dos estudantes onde a forma como é realizada a avaliação e os dispositivos utilizados enquanto contínua, formativa ou sumativa; os aspectos sociais/relacionais/comportamentais entre estudantes e docentes/tutores, como acontecem as relações sociais nos espaços online e, por fim; os aspectos de usabilidade do curso, fácil acesso e flexibilidade na plataforma utilizada e nos materiais disponibilizados.

Com essas unidades iniciamos a construção do guião do instrumento e a categorização dessas unidades, como podemos visualizar no quadro a seguir. A categorização dessas unidades foi elaborada a partir dos referenciais clássicos e teóricos da didática e pedagogia; para além disso, também realizamos uma pesquisa sobre os temas da didática no online e em contextos assíncronos (Amador, Nobre, Barros, 2016; Mello \& Barros, 2014). É um tema que cautela a estrutura dos cursos e a forma como se trabalha para facilitar a aprendizagem do estudante através dos eixos da inclusão, literacia do digital, design universal, personalização e estilos de aprendizagem.

\section{Guião de Construção do Instrumento}

Os guiões de construção dos instrumentos são essenciais para a revisão, fundamentação e direcionamento, de acordo com o referencial teórico e os objetivos propostos. O guião contemplou os objetivos, as unidades de contexto, os indicadores e as informações e/ou escalas.

Quadro 5: Unidades de contexto e categorias do guião de realização do instrumento. Pereira et al (2007) e demais fundamentações que sustentam os aspetos pedagógicas do eLearning, como: Rudestan \& Read-Schoenholt (2010), Garrison (1989), Aretio et al (2007), Anderson (2005). Garrison \& Anderson (2003), Downes (2007).

\begin{tabular}{|c|c|c|c|}
\hline Objetivos & $\begin{array}{c}\text { Unidades de Contexto (referências } \\
\text { pedagógicas) }\end{array}$ & Indicadores a serem observados & $\begin{array}{l}\text { Informação de } \\
\text { identificação e } \\
\text { escala utilizada }\end{array}$ \\
\hline $\begin{array}{lr}\text { Caracterizar } & \text { o } \\
\text { curso } \quad e & o \\
\text { contexto } & d a \\
\text { empresa } & \end{array}$ & Avaliadores & $\begin{array}{l}\text { Data: } \\
\text { Procedimentos: } \\
\text { Metodologia: }\end{array}$ & \\
\hline & Caracterização do curso & Nome do Curso: & \\
\hline
\end{tabular}

RPGE- Revista on line de Política e Gestão Educacional, Araraquara, v.21, n.3, p. 1517-1549, set./dez., 2017. 


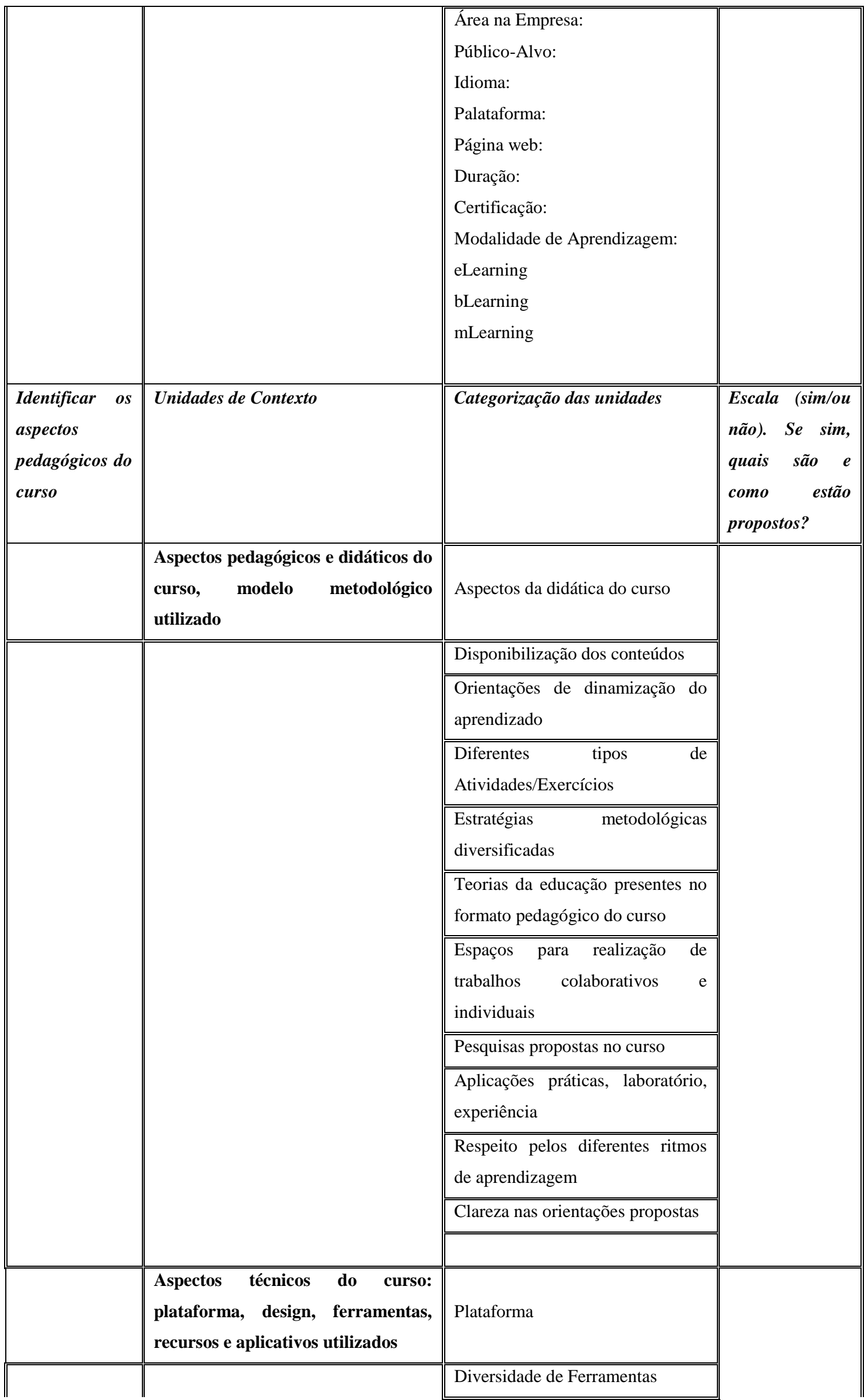

RPGE- Revista on line de Política e Gestão Educacional, Araraquara, v.21, n.3, p. 1517-1549, set./dez., $2017 . \quad$ ISSN: 1519-9029 DOI: 10.22633/rpge.v21.n3.2017.10971 


\begin{tabular}{|c|c|}
\hline & Recursos abertos \\
\hline & Objetos de aprendizagem \\
\hline & Vídeos \\
\hline & Podcast \\
\hline & Repositórios \\
\hline & Wikis \\
\hline & Blogs \\
\hline & Imagens \\
\hline & Redes Sociais \\
\hline 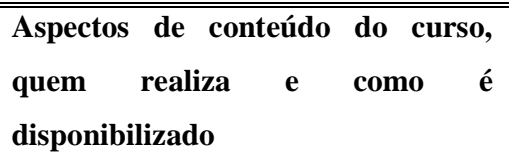 & Material elaborado \\
\hline & Indicação de livro \\
\hline & "Artigos, textos, orientações \\
\hline & Diversidade de níveis de material \\
\hline & Material complementar \\
\hline & $\begin{array}{lll}\text { Diversidade } & \text { de } & \text { formatos } \\
\text { disponibilizado } & & \\
\end{array}$ \\
\hline & $\begin{array}{l}\text { Rigor científico e qualidade dos } \\
\text { materiais }\end{array}$ \\
\hline $\begin{array}{lcr}\text { Aspectos } & \text { assíncronos } & \text { de } \\
\text { comunicação e interação entre } & \text { entantes e formadores/tutores - } \\
\text { estudáns } & & \\
\text { Fóruns }\end{array}$ & $\begin{array}{l}\text { Dinâmicas de comunicação: } \\
\text { Fóruns, Reflexões, Comentários } \\
\text { Críticos, Diálogos, Dúvidas e } \\
\text { Perguntas. }\end{array}$ \\
\hline & $\begin{array}{l}\text { Tipos de comunicação: Síncrona, } \\
\text { Assíncrona ou Síncrona e } \\
\text { assíncrona }\end{array}$ \\
\hline & $\begin{array}{l}\text { Adequação de linguagem dos } \\
\text { materiais }\end{array}$ \\
\hline & $\begin{array}{l}\begin{array}{l}\text { Normas de comunicação, } \\
\text { etiqueta }\end{array} \\
\text { Net }\end{array}$ \\
\hline & $\begin{array}{l}\text { Tipos de interação que ocorrem no } \\
\text { curso (estudantes X formadores, } \\
\text { estudantes X estudantes, } \\
\text { estudantes X recursos) }\end{array}$ \\
\hline $\begin{array}{llll}\text { Aspectos } & \text { de } & \text { avaliação } & \text { dos } \\
\text { estudantes } & & & \\
\end{array}$ & $\begin{array}{l}\text { Tipo de avaliação (somativa, } \\
\text { formativa), contínua) }\end{array}$ \\
\hline & $\begin{array}{l}\text { Como é realizada: exercício, teste, } \\
\text { prova, presencial ou online }\end{array}$ \\
\hline
\end{tabular}

RPGE- Revista on line de Política e Gestão Educacional, Araraquara, v.21, n.3, p. 1517-1549, set./dez., $2017 . \quad$ ISSN: 1519-9029 


\begin{tabular}{|c|c|}
\hline & $\begin{array}{l}\text { Técnicas de avaliação: } \\
\text { Autoavalição; Heteroavaliação; } \\
\text { Avaliação entre pares. }\end{array}$ \\
\hline & $\begin{array}{l}\text { Tipos de perguntas: Abertas } \\
\text { (resposta longa, resposta curta), } \\
\text { Escolha-múltipla, outras. }\end{array}$ \\
\hline & $\begin{array}{l}\text { Trabalhos individuais } \text { ou } \mathrm{em} \\
\text { grupo }\end{array}$ \\
\hline & Feedback aos estudantes \\
\hline $\begin{array}{l}\text { Aspectos } \\
\text { sociais/relacionais/comportamentais } \\
\text { entre estudantes e docentes/ tutores }\end{array}$ & $\begin{array}{lll}\text { Existe alguma } & \text { rede } & \text { ou } \\
\text { comunidade interna } & & \\
\end{array}$ \\
\hline & $\begin{array}{l}\text { Existe um espaço de socialização } \\
\text { no ambiente }\end{array}$ \\
\hline & $\begin{array}{l}\text { Criam-se laços de confiança e } \\
\text { amizade entre os estudantes }\end{array}$ \\
\hline & Têm conexões com redes sociais \\
\hline & $\begin{array}{l}\text { Presencialidade virtual na } \\
\text { plataforma: qual é a assiduidade ? }\end{array}$ \\
\hline & $\begin{array}{l}\text { Comportamento geral no domínio } \\
\text { de valores e atitudes }\end{array}$ \\
\hline & Preconceitos e estereótipos \\
\hline Aspectos de usabilidade do curso & $\begin{array}{l}\text { A plataforma é de fácil acesso e } \\
\text { navegação }\end{array}$ \\
\hline & As cores e as letras \\
\hline & $\begin{array}{l}\text { O número de cliques para acesso } \\
\text { ao ambiente }\end{array}$ \\
\hline & $\begin{array}{l}\text { É funcional em } \text { qualquer } \\
\text { dispositivo móvel }\end{array}$ \\
\hline & Mapa de navegação do site \\
\hline & $\begin{array}{l}\text { Contempla facilidade de uso a } \\
\text { qualquer estudante } \\
\text { necessidades especiais }\end{array}$ \\
\hline
\end{tabular}

Fonte: Elaboração própria

Para a realização do guião, não se identificou uma teoria educacional clara ou um modelo pedagógico para dirigir a estrutura e funcionamento dos cursos em eLearning empresarial, portanto, considerando essa realidade e a partir desses elementos, foi desenvolvido o instrumento para identificação dos principais aspectos 
pedagógicos dos cursos. O levantamento de informações em bases de dados e revistas em três diferentes idiomas possibilitou encontrar algumas informações convergentes, mas não algo parecido com o instrumento proposto. $\mathrm{O}$ instrumento (anexo 1) trouxe respostas e argumentação para as questões propostas e as hipóteses construídas.

A validação desse instrumento foi realizada em duas etapas: primeiramente, o envio do instrumento para quatro professores doutores do Laboratório de Educação a Distância e eLearning da UAb - LE@D e dois professores doutores do Centro de Imigrações e Relações Interculturais da UAb - CMRI, que analisaram e fizeram algumas sugestões de melhoria; em seguida, testamos o instrumento na avaliação dos nossos próprios cursos enquanto docentes da educação a distância, fizemos alguns ajustes e aprimoramos o instrumento.

\section{Limitações do instrumento}

O trabalho com o eLearning em contexto empresarial precisa envolver diversas áreas da empresa e do ambiente, além das chefias e do interesse em expandir o tema. Esses elementos relacionados compõem a base de apoio necessário para o sucesso do investimento nesta iniciativa. Deve haver um interesse e mobilização efetiva dentro da empresa para que o projeto possa caminhar bem. Este ambiente empresarial pode ser um limitador para o teste e o desenvolvimento de investigações científicas.

Sobre o desenvolvimento do instrumento, as limitações estão em não ter sido aplicado em outros contextos empresariais e em mais cursos de eLearning. A oportunidade de aplicar em diversos locais seria essencial para testar e aprimorar o instrumento realizado.

Para além disso, a complexidade em realizar investigações científicas sobre o tema do eLearning empresarial, pela dificuldade em encontrar artigos e livros que tratem com propriedade o eLearning nestes contextos, justificando assim, de certa forma, o interesse e a apresentação desse trabalho.

A formação ao longo da vida é um tema de interesse das empresas, e o eLearning é a chave para o desenvolvimento contínuo e aperfeiçoamento das formas de aprendizagem e treinamento, por isso um tema que demanda especial cuidado e atenção, porque envolve a aprendizagem dos adultos em contextos diferenciados do escolar, mas que devem ter os mesmos padrões de qualidade e atenção para com o processo de ensino e aprendizagem. 


\section{Considerações finais}

O objetivo do instrumento foi caracterizar e elucidar os elementos pedagógicos dos cursos analisados em eLearning nos contextos empresariais. A construção do instrumento ocorreu, como já mencionado, nos cursos da empresa. Foram no total três cursos nos quais realizamos a observação. Esses cursos eram complemente online e tivemos acesso durante o trabalho que ali nos propusemos a desenvolver.

A partir da observação realizada, o que analisamos como elementos de importância para serem discutidos para cursos em eLearning foram os aspectos de natureza pedagógica e didática encontrados, como as estratégias metodológicas baseadas na apresentação de vídeos, contextualizando o tema e apresentando o assunto a ser desenvolvido; a metodologia de ensino centrada no docente com um caminho definido sem espaços de flexibilidade fora do planejado; algumas vezes os objetivos encontrados confundem-se com os objetivos dos docentes dos cursos e não se identificam claramente os objetivos que devem ser alcançados pelos estudantes que estão a realizar o curso; os cursos em geral são sequenciais, sem muita interação ou participação direta do estudante. Não há espaços de dúvidas, reflexões ou postagens para interação direta com um tutor; a metodologia é de autoformação; impossibilidade dos estudantes de controlarem o tempo de formação voltando ou revendo os conteúdos já visualizados em etapas anteriores no curso.

Os resultados destacam que é necessário intervir em toda a estrutura pedagógica vigente, focando-se mais na autonomia do estudante na avaliação. O desafio está em conseguir processar as alterações necessárias sem que isso interfira na missão, nos objetivos e nos valores da empresa, garantindo, assim, o sucesso e a competitividade da mesma.

Para além da construção do instrumento, o trabalho de observação realizado também contribuiu para a empresa. A partir dos elementos indentificados, em comparação com o modelo pedagógico da Universidade Aberta, pudemos realizar algumas sugestões pedagógicas que poderiam potencializar os espaços de interação dos estudantes com os conteúdos, com outros estudantes e com os docentes. As sugestões para os resultados identificados foram:

- Criação de espaços para a realização de trabalhos colaborativos (em grupo, entre os pares);

- Criação de espaços para pesquisas/literacia da informação, bem como espaços para aplicação prática/resolução de problemas reais; 
- Respeitar os diferentes ritmos de aprendizagem, adaptação e diversificação de atividades;

- Elaborar material didático-pedagógico, artigos, textos ou mesmo outro tipo de material complementar;

- Criação de um espaço de socialização no ambiente virtual; e

- Criação de um Módulo de Ambientação Online (MAO) para os estudantes iniciais.

Essas contribuições foram encaminhadas para a empresa em relatório final do trabalho realizado. O feedback foi positivo e de motivação para a melhoria e continuação das propostas que desenvolvem e que estão empenhados em realizar.

Sobre os principais objetivos do trabalho concluímos que pudemos alcançá-los, na medida em que construimos um instrumento de avaliação pedagógica para cursos em eLearning empresarial e, para além disso, apontámos algumas diretrizes didáticopedagógicas de análise para cursos em eLearning empresarial.

As duas hipóteses criadas para a investigação puderam ser analisadas, constatando que existe falta de modelos e referências de estruturas didático-pedagógicas na concepção dos cursos em eLearning empresarial. Para além disso, pudemos verificar que os cursos em eLearning empresarial não contemplam todos os elementos didáticopedagógicos para um curso online, em comparação com instituições educativas. Esses aspetos podem ser contornados pela diferença de objetivos e propósitos de cada contexto, sendo necessária a adaptação dos mesmos e justificando assim o que não está contemplado.

A grande inovação está na preocupação de romper fronteiras relativamente ao eLearning educacional, transpondo estes conceitos para o contexto empresarial. Destacamos elementos do eLearning em contexto empresarial, algumas características que fundamentam sua estrutura e forma de aplicação. Os referenciais utilizados ajudaram na identificação desses elementos nos estudos e investigações até agora realizados.

Como perspetiva de futuro, continuaremos o trabalho na área do eLearning empresarial e aplicaremos o instrumento em outros contextos para que possamos trazer mais resultados e aprimorar o trabalho em desenvolvimento.

\section{REFERÊNCIAS}

AMADOR, F.; NOBRE, A.; BARROS, D. Towards a model of a didactic of eLearning: an application to education for sustainable development, Handbook of 
Research on Engaging Digital Natives in Higher Education Settings, IGI GLOBAL. DOI: 10.4018/978-1-5225-0039-1.ch019, 2016.

ANASTASI, A.; URBINA, B. S. Testagem psicológica. Porto Alegre: ArtMed, 2000.

ANDERSON, T. Distance learning - Social software's killer ap? 17th Biennial Conference of the Open and Distance Learning Association of Australia (ODLAA). 2005. Disponível em:

<http://www.unisa.edu.au/odlaaconference/PPDF2s/13\%20odlaa\%20-

\%20Anderson.pdf $>$. Acesso em: 20 set. 2016.

ANDERSON, T. Theory and practice of online leanring. $2^{\mathrm{a}}$ ed. AU Press, Athabasca University, 2008.

ANDERSON, T.; KANUKA, H. E-Research, methods, strategies and issues. New York: Pearson Education, 2003.

ARETIO, L. G.; CORBELLA, M. R.; FIGAREDO, D. D. De la educación a distancia a la educación virtual. Barcelona: Editorial Ariel, 2007.

BARDIN, L. Análise de conteúdo. Lisboa, Edições 70,1977.

BOGDAN, R.; BIKLEN, S. Investigação Qualitativa em educação: uma introdução à teoria e aos métodos. Porto: Porto Editora, 1994.

BRENNAN, M. E-learning: Proving waste is a good thing. Chief Learning Officer, v. 3, p. 50-53, 2004.

BUENDIA. L. E.; CÓLAS P. B. (ORG.) Investigación educativa. 3 ed. Sevilha: Alfar, 1998.

BUENDIA. L. E.; CÓLAS, P. B. (ORG.) Análisis de la investigación educativa. Madrid: McGRAW-HILL, 1993.

CARDOSO, C. F. E BRIGNOLI, H. P. Os métodos da história: introdução aos problemas, métodos e técnicas da história. demográfica, econômica e social. São José: Universidad de Costa Rica, 1975.

CASTELLS, M. A sociedade em rede. 3ed. São Paulo: Paz e Terra, v. 1, 2000.

CASTELLS, M. A galáxia da internet: reflexões sobre a internet, os negócios e a sociedade. Rio de Janeiro: Zahar, 2003.

CEDEFOP (ED). The Challenge of e-learning in small enterprises. Luxembourg, 2003.

CLEMENTINO, A. Didática intercomunicativa em cursos online colaborativos.

Tese apresentada à Faculdade de Educação da Universidade de São Paulo, 2008.

Disponível em: <www.teses.usp.br/teses/disponiveis/48/48134/tde-

12062008.../Tesecompleta.pdf>. Acesso em: 13 fev. 2017 
D'ARISBO, A.; CISLAGHI, T. P.; FACHINELLI, A. C.; LARENTIS,

F. Criação de conhecimento sob a ótica da aprendizagem organizacional em uma empresa criativa. Brazilian Journal Of Management/Revista De Administração Da Ufsm. Jan-Mar, v. 9, Issue 1, p. 53-101, 2016.

DOWNES, S. e-Learning 2.0 in development. Brandon Hall Research Innovations in Learning Conference. San Jose, California, 2007. Áudio e slides disponíveis em: <http://www.downes.ca/presentation/149>. Acesso em: 20 mar. 2017.

FACHEL, J.; CAMEY, S. Avaliação psicométrica: a qualidade das medidas e o entendimento dos dados, p. 158-170. In J. A. Cunha e cols. Psicodiagnóstico. (v. 5, ed. rev.) Porto Alegre: Artmed, 2000.

GARRISON, R. Understanding Distance Education - a framework for the future. Routledge: London and New York, p. 139, 1989.

GARRISON, R.; ANDERSON, T. eLearning in the 21st Century: A Framework for Research and Practice. London \& New York: RoutledgeFalmer, 2003.

GARRISON, R.; ANDERSON, T.; ARCHER, W. Critical Inquiry in a textbased environment: Computer conferencing in higher education. Internet and HigherEducation, 11(2), 1-14, 2000.

GUTIERREZ, K. The 5 best ways to research your eleanring course target audience, 2015. Disponível em: <http://info.shiftelearning.com/blog/research-yourelearning-course-target-audience>. Acesso em: 20 mar. 2017.

HAMBURG, I.; LINDECKE, C. H. Blended learning - chance for vocational training in small and medium sized companies. In Jutz, C.; Hirt, M.; Rizek-Pfister, C. (eds.): 6th International Conference on New Educational Environments: the know-how hub for blended learning and media didactics, Neuchâtel, Switzerland, 27-30 September. Berne: net4net, 2004.

HAMBURG, I.; CERNIAN, O.; THIJ, H. Blended learning and distributed learning environments. In 5th International Conference on New Educational Environments: Lucerne, Switzerland - May 26-28, the know-how hub for blended learning. Berne: net4net, 2003.

HAMBURG, I., LINDECKE, C., TERSTRIEP, J. Elearning - a chance for small and medium sized enterprises. eleed, Iss. 2, 2005.

HAMBURG, I.; PUKLUS, Z.; OTTOFI, R. Problems and issues in eLearning for SMEs: interdisciplinary development teams. In 1st International Conference on Interdisciplinarity in Education: book of abstracts. Athens: ICIE, p. 51-52, 2005.

KAWULICH, B. B. Participant observation as a data collection method. In Forum: Qualitative Social Research, v. 6, n. 2, art. 43, 2005.

KEEGAN, D. Foundations of Distance Education. Routledge, London and New York; Routledge Studies in Distance Education; Third Edition, 1996.

RPGE- Revista on line de Política e Gestão Educacional, Araraquara, v.21, n.3, p. 1517-1549, set./dez., 2017. 
KIMILOGLU, H.; OZTURAN, M.; KUTLU, B. Elearning for comporate trainings in Turkey: an exploratory study. Business Management Dynamic. v. 3, Issue 3, 2013.

LACOTTE, J. The triangle of communicative didactique. In Aera Annual Meeting, News Orleans, 1994. Disponível em: <http://www.aera.net/Publications/Online-PaperRepository/AERA-Online-Paper-Repository>. Acesso em: 30 mar. 2017.

LATIESA, M. Validez e fiabilidad de las observaciones sociologicas. In F. M. Garcia, J. Ibáñez \& F. A. El analisis de la realidad social: métodos e técnicas de investigación. 2a ed, p. 335-364. Madri: Alianza,1996.

LEAL, C. P. P.; ROCIO, V. O elearning e a computação em nuvem nas organizações empresariais. Revista de Ciências da Computação [Em linha]. ISSN 1646-6330 (Print) 2182-1801 (Online). v. 9, n. 9, p. 91-104, 2014.

MELLO, D. E.; BARROS, D. M. V. Didática do Online. 2014. Disponível em: https://repositorioaberto.uab.pt/. Acesso em: 20 jun. 2017.

MOORE, M. Theory of transactional distance. New York: Routledge,1993.

MILL, U.; BONNEMANN, D.; PAUL, H. E-Learning in KMU: Stolpersteine auf dem Weg zur Wissensgesellschaft. In: Institut Arbeit und Technik: Jahrbuch 2003/2004. Gelsenkirchen, p. 69-82, 2004.

MORAIS, C. Escalas de medida, estatística descritiva e inferência estatística. 2005. Disponível em: <http://maiorblogdainternet.blogspot.pt/2013/03/tipos-de-dadosnominal-ordinal.html>. Acesso em: 15 jun. 2017.

PAPPAS, C. How to Effectively Analyse your eLeanring Course Audiences. In Elearning Industry, 2014. Disponível em: <https://elearningindustry.com/6-keyquestions-to-effectively-analyze-your-elearning-course-audiences $>$. Acesso em: 15 jul. 2017.

PASQUALI, L. Teoria e métodos de medida em ciências do comportamento. Brasília: Laboratório de Pesquisa em Avaliação e Medida da Universidade de Brasília, 1996.

PEREIRA, A.; QUINTAS MENDES, A.; MORGADO, L.; AMANTE, L.; BIDARRA, J. Modelo Pedagógico Virtual da Universidade Aberta, Lisboa, Universidade Aberta, 2007.

PETERS, O. Didática do ensino a distância. Tradução Ilson Kayser. Editora Unisinos, São Leopoldo, 2001.

PILLA, B. S. Elearning Corporativo: estrutura e avaliação. Jundiaí: Paco Editorial, 2016.

RENÉE E. D.; BARBARA, A. F. E-learning in organizations. In Journal of Management, v. 31, p. 920, 2005. Disponível em: 
<https://studysites.uk.sagepub.com/wilton/Online\%20readings/Chapter\%209/Derouin, \%20Fritsche\%20and\%20Salas\%20article.pdf>. Acesso em: 20 ago. 2017.

ROSENBERG, M.J. eLearning: estratégias para a transmissão do conhecimento na era digital. São Paulo: Makron Books, 2002.

RUDESTAN, K.E; READ-SCHOENHOLTZ. J. Handbook of online Learning. SAGE: Unites Estates of American, 2010.

SANTOS, A. M. Projetos de e-Learning Inovação: Implementação e Gestão. Lidel, 2014.

SAUNDERS, M. N. K.; LEWIS, P.; THORNHILL, A. Research methods for business. Pearson: England, 2000. Disponível em: <https://is.vsfs.cz/el/6410/leto2015/BA_BSeBM/um/um/Research_Methods_for_Busin ess_Students_5th_Edition.pdf>. Acesso em: 20 jul. 2017.

SCHNEIDER, S.; SCHIMITT, C. J. O uso do método comparativo nas Ciências Sociais. Cadernos de Sociologia, Porto Alegre, v. 9, p. 49-87, 1998.

SKILLSOFT. E-learning in USA \& Canada benchmark survey. Nashua, OH: Author students. England: Pearson Education, 2001.

THOMPSON, M.M. J. Evaluating online courses and programs. Journal of Computing Higher Education. v. 15, p. 63, 2004.

WADE, R. What happens when you hear the term 'Blended Learnings'? 2003.

Disponível em: <https://www.elearningeuropa.info/en/article/What-happens-when-youhear-or-see-the-term-\%E2\% 80\%98Blended-Learning\%E2\%80\%99\%3F $>$. Acesso em: 20 jun. 2017.

\section{Como referenciar este artigo}

BARROS, Daniela Melaré Vieira.; NEVES, Cláudia. Instrumento para identificação dos elementos pedagógicos do elearning no cenário empresarial. Revista on line de Política e Gestão Educacional, Araraquara, v.21, n.3, p. 1517-1549, set./dez., 2017. ISSN: 1519-9029.

Submetido em: 20/08/2017

Aprovado em: 30/11/2017 
Anexo 1 -Instrumento para ser aplicado

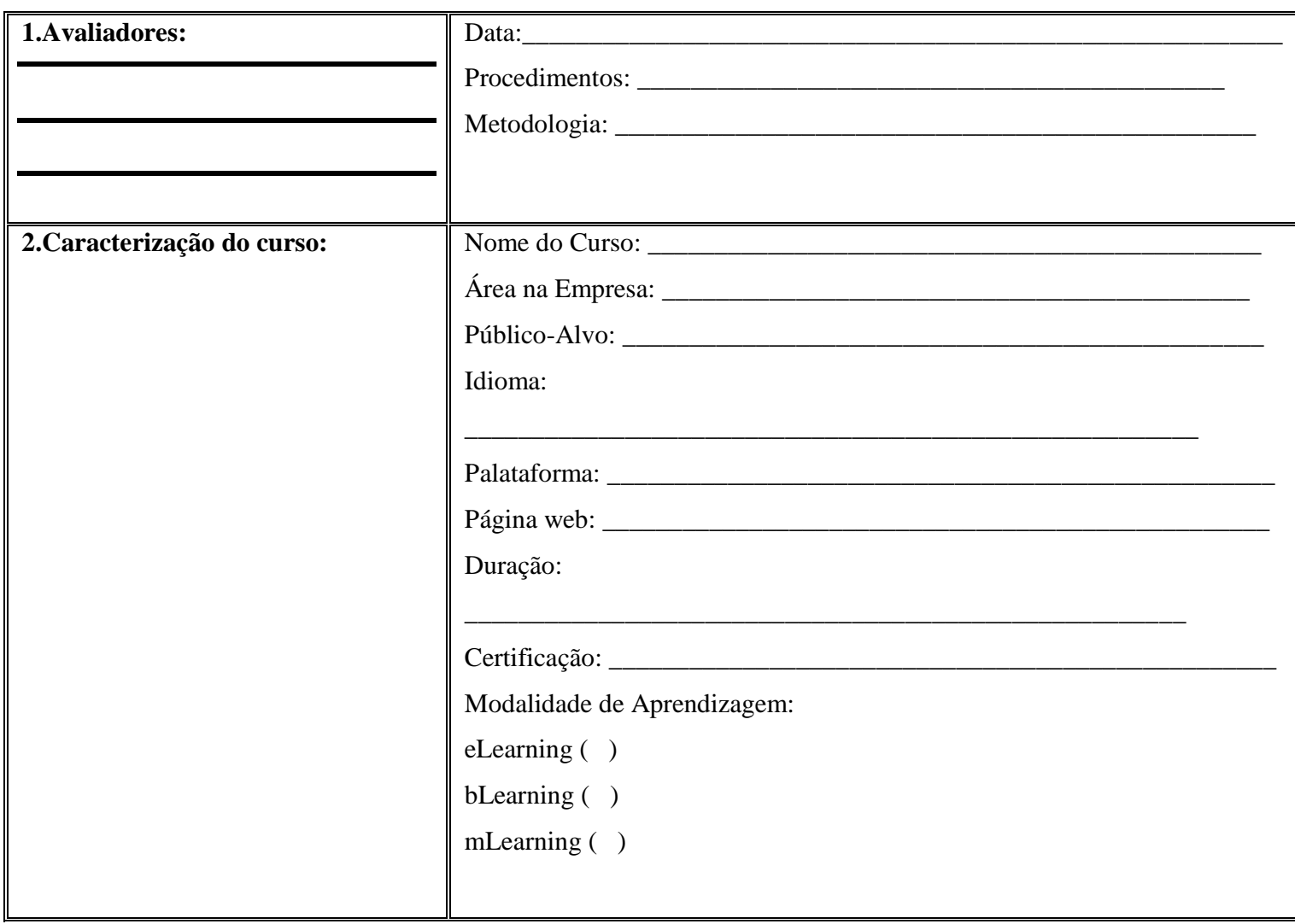

\begin{tabular}{|c|c|c|}
\hline Unidades de Contexto & Categorização das unidades & $\begin{array}{l}\text { Escala (sim/ou não). Se sim, quais são } \mathrm{e} \\
\text { como estão propostos? }\end{array}$ \\
\hline \multirow{11}{*}{$\begin{array}{l}\text { 3.Aspectos pedagógicos e } \\
\text { didáticos do curso, } \\
\text { modelo metodológico } \\
\text { utilizado }\end{array}$} & Aspectos da didática do curso & \\
\hline & Disponibilização dos conteúdos & \\
\hline & Orientações de dinamização do aprendizado. & \\
\hline & Diferentes tipos de Atividades/ Exercícios & \\
\hline & Estratégias metodológicas diversificadas & \\
\hline & $\begin{array}{l}\text { Teorias da educação presentes no formato } \\
\text { pedagógico do curso }\end{array}$ & \\
\hline & $\begin{array}{l}\text { Espaços para realização de trabalhos } \\
\text { colaborativos e individuais }\end{array}$ & \\
\hline & Pesquisas propostas no curso & \\
\hline & Aplicações práticas, laboratório, experiência & \\
\hline & Respeito aos diferentes ritmos de aprendizagem & \\
\hline & Clareza nas orientações propostas. & \\
\hline $\begin{array}{l}\text { 4.Aspectos técnicos do } \\
\text { curso: plataforma, }\end{array}$ & Plataforma & \\
\hline
\end{tabular}

RPGE- Revista on line de Política e Gestão Educacional, Araraquara, v.21, n.3, p. 1517-1549, set./dez., $2017 . \quad$ ISSN: 1519-9029 DOI: 10.22633/rpge.v21.n3.2017.10971 
design, ferramentas, recursos e aplicativos utilizados

5.Aspectos de conteúdo do curso, quem realiza $e$ como é disponibilizado

6.Aspectos assíncronos de comunicação e interação entre estudantes e

formadores/ tutores Fóruns

7.Aspectos de avaliação dos estudantes

\begin{tabular}{|c|c|}
\hline \multicolumn{2}{|l|}{ Diversidade de Ferramentas } \\
\hline \multicolumn{2}{|l|}{ Recursos abertos } \\
\hline \multicolumn{2}{|l|}{ Objetos de aprendizagem } \\
\hline \multicolumn{2}{|l|}{ Vídeos } \\
\hline \multicolumn{2}{|l|}{ Podcast } \\
\hline \multicolumn{2}{|l|}{ Repositórios } \\
\hline \multicolumn{2}{|l|}{ Wikis } \\
\hline \multicolumn{2}{|l|}{ Blogs } \\
\hline \multicolumn{2}{|l|}{ Imagens } \\
\hline \multicolumn{2}{|l|}{ Redes Sociais } \\
\hline \multicolumn{2}{|l|}{ Material elaborado } \\
\hline \multicolumn{2}{|l|}{ Indicação de livro } \\
\hline \multicolumn{2}{|l|}{ Artigos, textos, orientações } \\
\hline \multicolumn{2}{|l|}{ Diversidade de níveis de material } \\
\hline \multicolumn{2}{|l|}{ Material complementar } \\
\hline \multicolumn{2}{|l|}{ Diversidade de formatos disponibilizado } \\
\hline \multicolumn{2}{|l|}{ Rigor científico e qualidade dos materiais } \\
\hline \multicolumn{2}{|l|}{$\begin{array}{l}\text { Dinâmicas de comunicação: Fóruns, Reflexões, } \\
\text { Comentários Críticos, Diálogos, Dúvidas e } \\
\text { Perguntas. }\end{array}$} \\
\hline \multicolumn{2}{|l|}{$\begin{array}{l}\text { Tipos de comunicação: Síncrona, Assíncrona ou } \\
\text { Síncrona e assíncrona }\end{array}$} \\
\hline \multicolumn{2}{|l|}{ Adequação de linguagem dos materiais } \\
\hline \multicolumn{2}{|l|}{ Normas de comunicação, Net etiqueta } \\
\hline \multicolumn{2}{|l|}{$\begin{array}{l}\text { Tipos de interação que ocorre no curso } \\
\text { (estudantes } \mathrm{X} \text { formadores, estudantes } \mathrm{X} \\
\text { estudantes, estudantes } \mathrm{X} \text { recursos) }\end{array}$} \\
\hline \multicolumn{2}{|l|}{$\begin{array}{l}\text { Tipo de avaliação (somativa, formativa), } \\
\text { contínua) }\end{array}$} \\
\hline \multicolumn{2}{|l|}{$\begin{array}{l}\text { Como é realizada: exercício, teste, prova, } \\
\text { presencial ou online }\end{array}$} \\
\hline \multicolumn{2}{|l|}{$\begin{array}{l}\text { Técnicas de avaliação: Auto-avalição; } \\
\text { Heterovaliação; Avaliação entre pares }\end{array}$} \\
\hline \multicolumn{2}{|l|}{$\begin{array}{l}\text { Tipos de perguntas: Abertas (resposta longa, } \\
\text { resposta curta), Escolha-múltipla, outras. }\end{array}$} \\
\hline Trabalhos individuais ou em grupo & \\
\hline
\end{tabular}




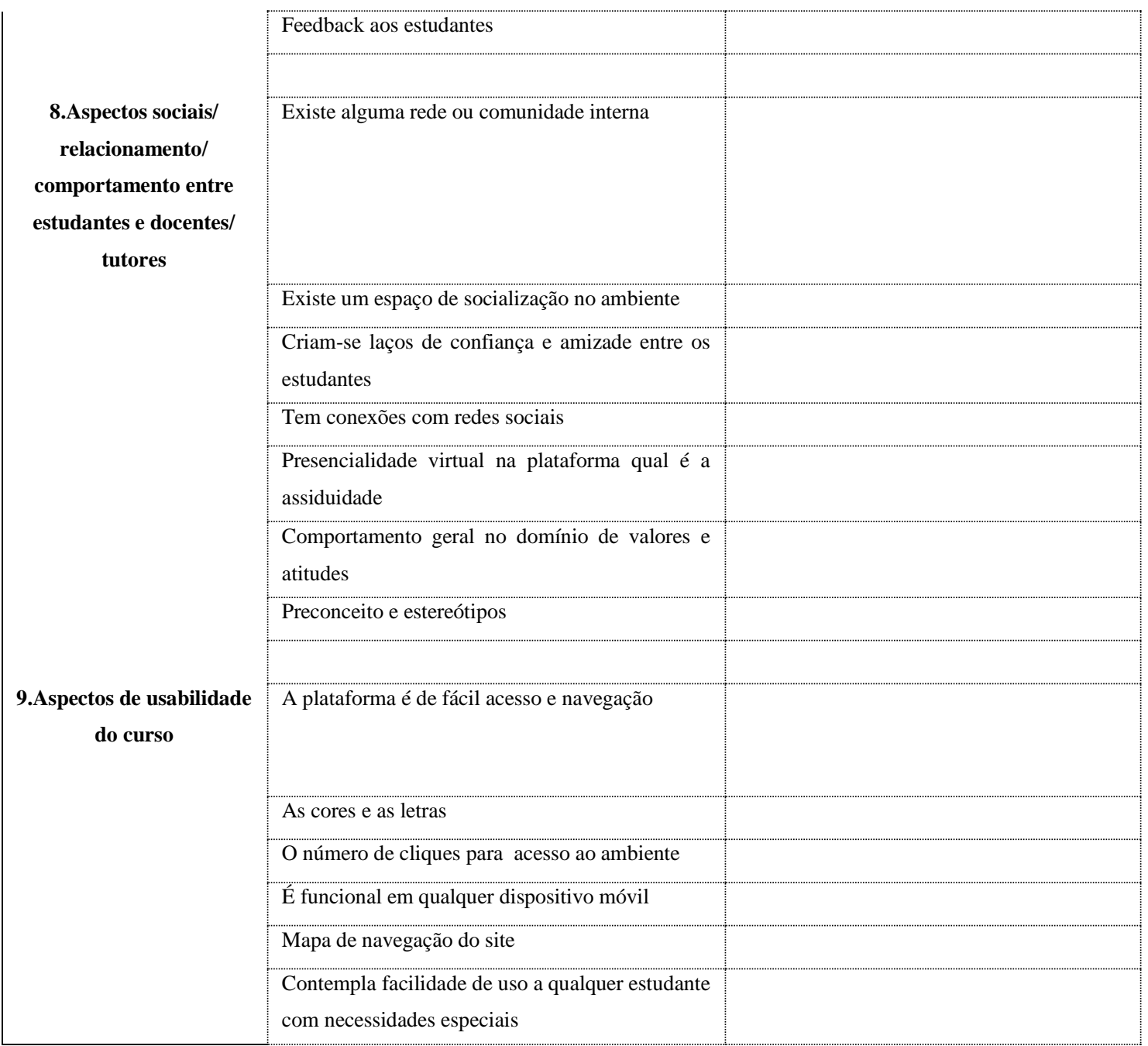

